\title{
Effect of temperature on early-age properties of self-consolidating concrete equivalent mortar
}

\author{
Nima Farzadnia ${ }^{1}$, Jing Pan $^{2,3}$, Kamal Khayat ${ }^{1 *}$, Eric Wirquin ${ }^{3}$ \\ ${ }^{1}$ Missouri University of Science \& Technology, Rolla, MO, USA \\ ${ }^{2}$ Université de Sherbrooke, Sherbrooke, Qc, Canada \\ ${ }^{3}$ Université de Lille Nord de France, Laboratory of Civil and geoEnvironmental Engineering (LGCgE), France
}

Received: 06 April 2020 / Accepted: 18 November 2020 / Published online: 22 December 2020

(C) The Author(s) 2020. This article is published with open access and licensed under a Creative Commons Attribution 4.0 International License.

\begin{abstract}
In this study, the effect of ambient temperature during casting on fresh properties, hydration kinetics, and early-age compressive strength of selfconsolidating concrete (SCC) was evaluated. Concrete equivalent mortars (CEMs) with water-to-binder ratios of 0.41 and 0.45 were cast based on SCC mixture designs for building and infrastructure construction and precast applications. The CEMs were prepared at temperatures ranging from 8 to $36^{\circ} \mathrm{C}$. Superplasticizer (SP) and air-entraining agent (AEA) demand were evaluated for the CEM mixtures made with different supplementary cementing material (SCM) and limestone filler types. Test results showed that the ambient temperature can significantly affect the SP and AEA demand, hydration kinetics, and compressive strength at 1 day. For a constant slump flow and air content, the demand of the SP and AEA, heat flux, and 1-d compressive strength of CEMs increased linearly with material temperature.
\end{abstract}

Keywords: Temperature; Self-consolidating concrete; Concrete equivalent mortar; Early-age properties

\section{Introduction}

Self-consolidating concrete (SCC) is a highly workable concrete that flow under its own weight and can encapsulate reinforcing bars in restricted sections, with minimum risk of segregation. The production of SCC requires an adequate compromise between flowability, passing ability, and stability that can be achieved by optimum mixture formulation and adequate use of chemical admixtures, supplementary cementitious materials (SCMs), and fillers. The ambient and concrete temperatures can have a marked effect on the rheological properties and their rate of change during transport and placement.

The influence of temperature on concrete at the fresh state [1-4] is mainly attributed to the intertwining effect of temperature on hydration kinetics of the binder and performance of the chemical admixtures. Temperature affects cement hydration through mechanisms that govern kinetics, such as dissolution, nucleation, or precipitation rates, as well as diffusion through the hydrates assemblage around unreacted cement grains [5-9]. The material temperature can accelerate/decelerate cement hydration, which influences the quantity of C-S-H and portlandite and other hydration products during the first hours of hydration. Lothenbach et al. [7] found that there was a significant decrease of sulfate and $\mathrm{Ca}^{+2}$ ion concentrations between 3 to $6 \mathrm{~h}$ at $50^{\circ} \mathrm{C}$. The rapid increase of alkali concentration in the pore solution indicates that the hydration takes place at a more rapid pace than that at $20^{\circ} \mathrm{C}$. On the contrary, ettringite was formed as a dominant hydration product after $6 \mathrm{~h}$ at $5^{\circ} \mathrm{C}$, and portlandite and some $\mathrm{C}-\mathrm{S}-\mathrm{H}$ were mainly detected after one day [7]. The significant decrease of the sulfate and $\mathrm{Ca}^{+2}$ concentrations was observed after more than 1 day. Such changes in the formation of hydration products by variation in temperature can affect the time dependant steric dispersion effect of the superplasticizer (SP). For example, the dispersion effect of polycarboxylate ether superplasticizers (PCE) is greatly dependent on hydration kinetics and originates from the interaction of negatively charged backbones of the PCE molecules with positively charged clinker and reaction phases, like $\mathrm{C}_{3} \mathrm{~A}$ and ettringite [3]. In this process, SP molecules compete with sulphate ions and interact with calcium ions in the pore solution [4, 5]. Temperature causes a conflicting effect on fresh properties of SCC. Increasing temperature can accelerate hydration causing a quicker render of C-S-H and faster loss of workability. On the other hand, increased temperature can accelerate the growth of ettringite, which provides larger adsorption sites for the SP. Decreasing the temperature decelerates structuration of the system by slowing down the rate of hydration, which leads to fewer adsorption sites available to activate the steric function of SPs

\footnotetext{
* Corresponding author: Kamal Khayat, Email: khayatk@mst.edu
} 
[10]. This can increase the amount of ineffective steric particles in the solution. These conflicting mechanisms are reflected in the reported literature. Mehdi and Martini [11] showed that the increase of temperature from $20^{\circ} \mathrm{C}$ to $45^{\circ} \mathrm{C}$ did not affect the efficiency of PCE. On the other hand, Schmidt et al. [12] showed that PCE polymeric structure (backbone size) and solid content can greatly affect the performance of PCE at different temperatures. The authors reported that PCE with high ionic strength of the backbone can cause rapid stiffening at high temperatures. On the other hand, PCE with higher solid contents can delay the setting and heat flow at lower temperatures, which is detrimental for cold climate concrete construction.

The effect of SP can change with the type of SCM and chemical admixture, such as viscosity modifying admixture (VMA) and air entraining admixture (AEA). Petit et al. [13] reported that mixture temperature and type of SCM influenced the evolution of rheology with time in mortars made with PCE. Reportedly, the temperature has a significant effect on the rate of adsorption of PCE onto cement grains, rate of cement hydration, concentration of ions in aqueous solution, hydration layers growing from the surface area of cement grains, and steric size of polymer resulting in a higher initial yield stress values [14][15][16][17]. Petit et al. [13] also reported that the yield stress and plastic viscosity were found to vary linearly with time and temperature for mortar mixtures made with polynaphtalene- and polymelaminebased SP.

Kuehne et al. (2007) [18] reported that temperature changes had a greater effect on the effectiveness of PCE on slump flow, when VMA and PCE were used simultaneously in SCC. At $30 \cong \mathrm{C}$, the slump flow of concrete containing a combination of VMA and PCE decreased by $60 \%$ when the concrete

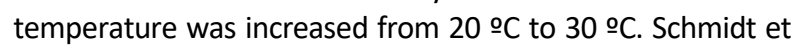
al. [12] studied the combined effect of two VMAs (starch ether and Diutan gum[12]) and two PCE types (with high and low ionic backbone structures) on the rheology of concrete

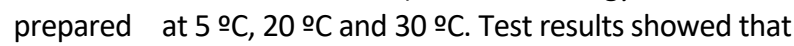
starch ether was less prone to temperature changes than Diutan gum. The authors found the charge density of the polymers' backbone and the solid content of PCE are critical to achieve certain flowability at varying temperatures. They explained that precipitation of aluminates and solubility of sulfates were slowed down at lower temperature, resulting in fewer adsorption sites for the PCE SP. PCE with higher backbone charge was more effective than that with low charge density.

Temperature also affects the efficiency of the AEA in stabilizing small and well-distributed air bubbles as well as AEA's solubility in the mixture. The foaming ability of the AEA changes in the same direction as the variation of solubility [19]. Dodson [20] found that with an increase in mixture temperature, the tendency and rate of insoluble AEA to coagulate became higher, and the foaming ability was lessened. An excessive amount of electrolytes in the solution, especially polyvalent ions, can further reduce the air bubble stability by reducing the electrostatically induced disjoining pressure [20]. Furthermore, the rate of hydration is another critical factor on AEA performance as the hydration products can adsorb some of the AEA from the liquid phase, thus affecting the air-void system and the stability of the air bubbles [21]. At high temperatures, upon hydration acceleration, more AEA is adsorbed onto hydration products, and less AEA can remain in the solution, thereby the air content is reduced.

As shown above, material temperature can significantly affect the kinetics of cement hydration and flowability of cementbased materials. The degree of influence of temperature is shown to vary with the SCM and chemical admixtures in use. Limited studies aimed at evaluating the effect of material temperature on the effectiveness of chemical admixtures and fresh properties of SCC made with different SCMs or fillers that are used at relatively high substitution rates in such concrete. This study investigated the effect of material temperature of concrete equivalent mortar (CEM) mixtures proportioned with different types of SCMs and chemical admixtures. Accordingly, the effect of material temperature ranging from $8{ }^{\circ} \mathrm{C}$ to $36^{\circ} \mathrm{C}$ that are common in construction on cement hydration, admixture demand, and early-age compressive strength of CEM was studied. Of special interest in this study is the flowability and early-age strength of CEMs that are representative of SCC mixtures used for building and prestressed applications and superworkable concrete for infrastructure construction. The study aims at evaluating the couple effect of temperature and type and content of SCMs and chemical admixtures on these properties of highperformance concretes with adapted rheology.

\section{Experimental program \\ 2.1 Materials}

In this study, three CEM mixtures were prepared to represent SCC mixtures designated for building construction (MB) and precast application (MP) and superworkable concrete designed for infrastructure construction (MI). The cement used in the MB and MP mixture was a CEM I $52.5 \mathrm{~N}$ Portland cement with a Blaine fineness of $420 \mathrm{~m}^{2} / \mathrm{kg}$. Its $C_{3} S$ and $C_{3} A$ contents are $60 \%$ and $8.5 \%$, respectively. The $\mathrm{MI}$ mixture was prepared with a GU Portland cement with a Blaine fineness of $400 \mathrm{~m}^{2} / \mathrm{kg}$. The $C_{3} S$ and $C_{3} A$ contents are $54 \%$ and $7.2 \%$, respectively. A natural sand with density and water absorption of $2.62 \mathrm{~g} / \mathrm{cm}^{3}$ and $1.63 \%$, respectively, was used for all the mixtures.

A Class F fly ash (FA), a Grade 100 slag cement (S), silica fume (SF), and limestone filler (LF) were used for partial replacement of the Portland cement in the various mixtures. The Blaine fineness of FA, S, and LF were 250,360 , and 530 $\mathrm{m}^{2} / \mathrm{kg}$, respectively. The BET fineness of silica fume was 18200 $\mathrm{m}^{2} / \mathrm{kg}$. The LP contained $97.2 \% \mathrm{CaCO}_{3}$. Table 1 summarizes the physical properties and chemical compositions of the portand cement, FA, and S used in this study.

Two polycarboxylate SPs (denoted as PCE1 and PCE2) complying with the requirements of Types A and F (ASTM C494 [22]), respectively, and a sodium polynaphtalene sulfonate based SP (PNS) were used. The PCE SPs had the water reduction capability of up to $45 \%$ and are suitable for both ready mix and precast applications. 
Table 1. Cement, fly ash, and slag properties.

\begin{tabular}{|l|l|l|l|l|l|l|l|}
\hline & $\mathrm{SiO}_{2}, \%$ & $\mathrm{Al}_{2} \mathrm{O}_{3}, \%$ & $\mathrm{Fe}_{2} \mathrm{O}_{3}, \%$ & $\mathrm{CaO}, \%$ & $\mathrm{MgO}, \%$ & $\mathrm{SO}_{3}, \%$ & $\mathrm{Specific}_{2}, \mathrm{Grvity}$ \\
\hline Cement GU & 20.8 & 4.3 & 2.4 & 62.5 & 2.2 & 3.5 & 3.2 \\
\hline CEM I 52.5 N & 20 & 5.1 & 3.3 & 63.9 & 0.8 & 3.1 & 3.2 \\
\hline Fly ash & 53.9 & 21 & 10.2 & 2.9 & 5.0 & 1.4 & 2.5 \\
\hline Slag & 36.8 & 9.2 & 0.76 & 37.1 & 9.5 & 0.1 & 2.9 \\
\hline
\end{tabular}

The solid contents of the PCE1 and PCE2 admixtures are $39 \%$ and $40.4 \%$, respectively, and that of the PNS is $41 \%$, as indicated in Table 2. A polysaccharide-based VMA in liquid form conforming to the requirement of ASTM C 494/AASHTO M 194 [23], suitable for both ready mix and precast applications, was used. An S type AEA, with an aqueous solution of organic materials conforming with ASTM C 260 [24] was used.

\subsection{Mixture proportioning and sample preparation}

The CEMs corresponding to the three reference concrete mixtures were designed by replacing the coarse aggregate with sand of an equivalent surface area. Good relationships between the rheological properties of the concretes and key properties of the corresponding CEMs are established $[25,26]$. This includes rheological properties and their variations in time, water reduction capacity, setting time, and compressive strength at the early age.

In total, $10 \mathrm{CEM}$ mixtures were investigated. The mixture proportioning of the CEMs are shown in Table 2. The MB, MP, and $\mathrm{Ml}$ groups encompassed four, two, and four series of mixtures, respectively. Based on the proposed application of each group, the water-to-binder ratio (w/b), SCM type, and type and content of chemical admixtures of each series was varied.

The CEMs were prepared in batches of six liters using a mixing speed of $140 \pm 5 \mathrm{rpm}$. The mixing procedure complied with ASTM C 305 [27]. The SP was mixed with $1 / 3$ of the total mixing water after a homogenous mixing of the sand (mixed with another $1 / 3$ of the total mixing water) and binder. The VMA and AEA were mixed separately with the remaining mixing water and were added after the SP. The materials and equipment were pre-conditioned in temperature-controlled chambers to secure the target temperatures for freshly cast CEMs within $\pm 1^{\circ} \mathrm{C}$. The mixing and the tests on fresh CEMs were prepared in environmental chambers of relative humidity values of $70 \%, 50 \%, 40 \%, 35 \%$, and $30 \%$, corresponding to the targeted temperatures of $8{ }^{\circ} \mathrm{C}, 15^{\circ} \mathrm{C}, 20$ ${ }^{\circ} \mathrm{C}, 29^{\circ} \mathrm{C}$, and $36^{\circ} \mathrm{C}$, respectively. All mixtures were protected from evaporation during testing; however, high temperature of materials during mixing can cause low relative humidity and partial evaporation of the mixing water, resulting in the loss of workability $[28,29]$. Although not measured, it was suspected that a portion of the mixing water was evaporated or absorbed by hydration phases, particularly ettringite once the water came in contact with the sand and binder at relatively high temperatures. It was also assumed that during the cement hydration process, the capillary tension and adsorbed water of hydrated cement paste partially evaporated due to the low relative humidity and elevated temperature, thus contributing to overall loss in slump flow
[30]. After mixing at the proposed temperatures, mixtures were maintained at room ambient conditions.

\subsection{Testing procedure}

The effect of temperature on flowability and early-age properties of CEM mixtures was determined by showing the effect of temperature on the SP demand in the CEM mixtures. To enable the calculation of the targeted mini-slump spread of the CEM mixtures, the average concrete thickness at the end of the slump flow test was calculated by dividing the volume of concrete in the slump cone to the total area of slump spread [26]. This thickness was then normalized by calculating the ratio ' $r$ ' of the average concrete thickness to the maximum aggregate size of SCC (Eq. 1).

$$
r=V_{s c C} /[\text { AscC * (Dmax)scc }]=V_{\text {CEM }} /\left[A_{C E M} *(D m a x)_{\text {CEM }}\right]
$$

where, $V_{\text {scc }}$ is the volume of SCC in the slump cone $\left(5495 \mathrm{~cm}^{3}\right)$; $A_{s c c}$ is the area of SCC slump flow; (Dmax) scc is the maximum aggregate size of the concrete; $\mathrm{V}_{\text {CEM }}$ is the volume of CEM in mini-slump cone $\left(287 \mathrm{~cm}^{3}\right)$; (Dmax) СЕM is the maximum aggregate size of the CEM ( $5 \mathrm{~mm}$ ); and $A_{C E M}$ is the area of CEM mini-slump flow. For each concrete slump flow value, the ' $r$ ' value was maintained constant for the corresponding CEM mixture.

The mini-slump cone used for the CEM had a height, top diameter, and a base diameter of $50 \mathrm{~mm}, 70 \mathrm{~mm}$, and 100 $\mathrm{mm}$, respectively, as per ASTM C1437 [31]. The MB and MP mixtures were placed in the mini cone by a single layer without any mechanical consolidation. However, the MI was less fluid and was placed in the mini cone in two layers and tampered by 10 strokes per layer to ensure full consolidation.

The initial slump flow values of the MB and MP mixtures were $260 \pm 10 \mathrm{~mm}$ and $250 \pm 10 \mathrm{~mm}$, respectively, which were derived from initial slump flow values of $660 \pm 20 \mathrm{~mm}$ of the SCC for building construction and $640 \pm 20 \mathrm{~mm}$ for precast application. The air content of each mixture was kept below $5 \%$. The MB and MP were not air entrained. VMA was incorporated in the MB and MP mixture to ensure adapted stability. The initial slump flow of the MI was $210 \pm 10 \mathrm{~mm}$, which corresponds to an initial slump flow $500 \pm 50 \mathrm{~mm}$ for the super workable concrete. The AEA content of the MI was adjusted to maintain an air content of $5 \% \pm 1 \%$ to enhance frost durability. The air content of CEMs was measured using a cylindrical container with an inner diameter of $76 \mathrm{~mm}$ and a height of $88 \mathrm{~mm}$. The MB and MP mixtures were cast in a single layer and were tampered five times. The MI mixture was cast in two layers and tampered by 10 times per layer. 
Table 2. Mixture proportioning of CEMs.

\begin{tabular}{|c|c|c|c|c|c|c|c|c|c|c|}
\hline \multirow{2}{*}{$\begin{array}{l}\text { Series } \\
\text { Mixture }\end{array}$} & \multicolumn{4}{|l|}{ MB } & \multicolumn{2}{|l|}{ MP } & \multicolumn{4}{|l|}{$\mathrm{Ml}$} \\
\hline & PCE1-FA & PCE1-LF & PNS-FA & PNS-LF & PCE2-FA & PCE2-SF & PCE1-FA & PCE1-S & PNS-FA & PNS-S \\
\hline$w / b$ & 0.45 & 0.45 & 0.45 & 0.45 & 0.41 & 0.41 & 0.41 & 0.41 & 0.41 & 0.41 \\
\hline $\begin{array}{l}\text { Cement CEM I } 52.5 \\
\mathrm{~N}\left(\mathrm{~kg} / \mathrm{m}^{3}\right)\end{array}$ & 490 & 490 & 490 & 490 & 500 & 640 & - & - & - & - \\
\hline Cement GU $\left(\mathrm{kg} / \mathrm{m}^{3}\right)$ & - & - & - & - & - & - & 420 & 420 & 420 & 420 \\
\hline $\begin{array}{l}\text { Class F Fly ash (FA) } \\
\left(\mathrm{kg} / \mathrm{m}^{3}\right)\end{array}$ & 160 & - & 160 & - & 170 & - & 150 & - & 150 & - \\
\hline $\begin{array}{l}\text { Limestone filler (LF) } \\
\left(\mathrm{kg} / \mathrm{m}^{3}\right)\end{array}$ & - & 160 & - & 160 & - & - & - & - & - & - \\
\hline Slag (S) $\left(\mathrm{kg} / \mathrm{m}^{3}\right)$ & - & - & - & - & - & - & - & 150 & - & 150 \\
\hline $\begin{array}{l}\text { Silica fume (SF) } \\
\left(\mathrm{kg} / \mathrm{m}^{3}\right)\end{array}$ & - & - & - & - & - & 35 & 30 & 30 & 30 & 30 \\
\hline Sand $\left(\mathrm{kg} / \mathrm{m}^{3}\right)$ & 1260 & 1260 & 1260 & 1260 & 1290 & 1320 & 1450 & 1450 & 1450 & 1450 \\
\hline $\begin{array}{l}\text { VMA\%, by liquid- } \\
\text { based mass of } \\
\text { binder }\end{array}$ & 0.142 & 0.142 & 0.142 & 0.142 & 0.055 & 0.055 & - & - & - & - \\
\hline $\begin{array}{l}\text { PCE1 } \quad(1.1 \quad \mathrm{~g} / \mathrm{ml} ; \\
\left.39 \%^{*}\right)\end{array}$ & $x$ & $x$ & - & - & - & - & $x$ & $x$ & - & - \\
\hline $\begin{array}{l}\text { PCE2 (1.1 } \mathrm{g} / \mathrm{ml} ; \\
\left.40.4 \%^{*}\right)\end{array}$ & - & - & - & - & $\mathrm{X}$ & $\mathrm{X}$ & - & - & - & - \\
\hline PNS (1.2 g/ml; 41\%*) & - & - & $\mathrm{x}$ & $\mathrm{X}$ & - & - & - & - & $\mathrm{x}$ & $\mathrm{x}$ \\
\hline $\begin{array}{l}\text { VMA } \quad(1.2 \quad \mathrm{~g} / \mathrm{ml} ; \\
\left.44 \%^{*}\right)\end{array}$ & $x$ & $x$ & $x$ & $x$ & $x$ & $x$ & - & - & - & - \\
\hline AEA (1 g/ml; 8.3\%*) & - & - & - & - & - & - & $x$ & $x$ & $x$ & $x$ \\
\hline
\end{tabular}

* a mass of solid admixture in solution

The heat of hydration was determined using an isothermal calorimeter. The test necessitated $75 \mathrm{~g}$ of freshly prepared mortar. All measurements lasted for $50 \mathrm{~h}$. A plane isothermal calorimeter developed by [9] was used in prisms with a square base and dimensions of $0.03 \mathrm{~m}$ by $0.15 \mathrm{~m}$. The flux meters were placed on the surface of the sample, which made it possible to measure the heat flux during hydration.

The compressive strength of the CEM mixtures was measured using cube samples measuring $50 \mathrm{~mm} \times 50 \mathrm{~mm} \times 50 \mathrm{~mm}$, according to ASTM C109 [32]. The samples were kept in an environmental chamber with the targeted temperatures and demolded after $24 \mathrm{~h}$ for testing in compliance with ASTM C 511 [33]. The average values of three samples were reported.

\section{Results and discussions}

\subsection{Effect of temperature on hydration kinetics}

Figure 1 shows the effect of temperature on the hydration kinetics of three CEM mixtures made with different SCM and SP types (Table 2). Figure 1a compares the effect of PNS and PCE1 on the hydration kinetics of the MB CEM mixtures made with FA contents at different temperatures. As shown, the major hydration peak of samples made with PNS was higher at elevated temperatures than mixtures made with PCE. Given the same mixture proportion, the results show that the PCE reduced the heat evolution at high temperatures when the FA was used. However, the incorporation of PCE and PNS did not have a significant influence on the acceleration of cement hydration, as the occurrence of the major peak of heat flow was almost at the same time.

The effect of elevated temperatures on the MB CEM mixtures made with LF was also dependant on the SP type. As shown in Fig. 1b, the major hydration peak recorded for samples prepared at higher temperatures showed that the CEM mixtures made with PCE1 experienced relatively higher rate of heat evolution; however, the hydration of those mixtures was decelerated. An comparison between Figs. 1a and 1b shows that the type of SCM changed the performance of PCE differently at elevated temperatures compared to those prepared with PNS (e.g., decrease of the heat flow with the presence of FA and deceleration of heat evolution for mixtures made with LF).

Figure 1c compares the effect of FA and SF on the hydration kinetics at different temperatures for the MP CEM mixtures made with PCE2. The increase in temperature resulted in higher heat evolution and acceleration of the hydration in the CEM made with SF. This can correspond to the higher reactivity and fineness of the SF compared to FA. However, at $8 \stackrel{\circ}{ }$, the impact of SF was reduced given the hindrance of cement hydration at lower temperature [7].

The heat flux of mixtures over time was also monitored using a plane isothermal calorimeter. The testing method involved the use of flux meters placed on the surfaces of the CEM mixtures with a square base of $0.03 \mathrm{~m}$ by $0.15 \mathrm{~m}$ to determined heat flux [9]. The heat flux was recorded for the initial 40 hours after the water-cement contact. At $22^{\circ} \mathrm{C}$, the maximum heat flux ( $\mathrm{F}$ max) was about $0.003 \mathrm{~W} / \mathrm{g}$ of cement for all compositions, which agrees well with the heat flow recorded using the isothermal calorimeter (Fig. 1).

Table 3 summarizes the maximum heat flux (Fmax) values determined for the investigated the CEM mixtures at different material temperatures. 

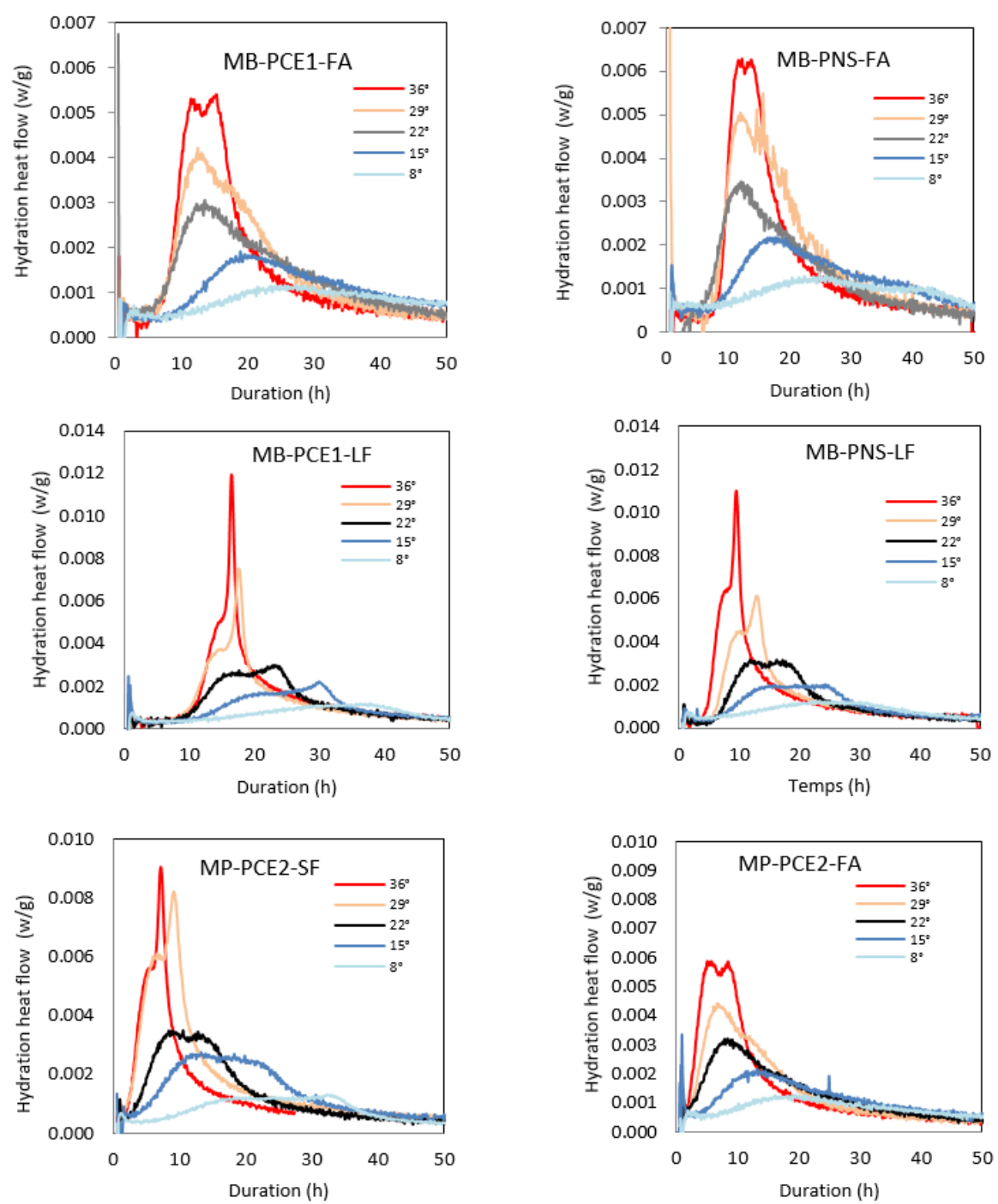

Figure 1. Hydration heat flow of CEM mixtures with different SPs and SCMs.

Table 3. Maximum heat flux for CEM mixtures at varying temperatures.

\begin{tabular}{l|l|l|l|l|l}
\hline \multirow{2}{*}{ Mixtures } & \multicolumn{4}{l}{ Heat flux $(\mathrm{w} / \mathrm{g})$} & \multicolumn{2}{l}{} \\
\cline { 2 - 6 } & $8\left({ }^{\circ} \mathrm{C}\right)$ & $15\left({ }^{\circ} \mathrm{C}\right)$ & $22\left({ }^{\circ} \mathrm{C}\right)$ & $29\left({ }^{\circ} \mathrm{C}\right)$ & $36\left({ }^{\circ} \mathrm{C}\right)$ \\
\hline MB- PCE1-FA & 0.001159 & 0.00192 & 0.006733 & 0.004214 & 0.005388 \\
MB-PNS-FA & 0.001356 & 0.002167 & 0.003465 & 0.008683 & 0.006293 \\
MB-PCE1-LF & 0.001202 & 0.002483 & 0.002991 & 0.007532 & 0.011957 \\
MB-PNS-LF & 0.001282 & 0.002019 & 0.003163 & 0.006158 & 0.010977 \\
MI- PNS-FA & 0.007284 & 0.004073 & 0.00379 & 0.005309 & 0.006893 \\
MI-PCE1-FA & 0.001619 & 0.002002 & 0.003323 & 0.004149 & 0.006006 \\
MP-PCE2-FA & 0.001299 & 0.00329 & 0.003234 & 0.004432 & 0.005896 \\
MP-PCE2-SF & 0.001344 & 0.002769 & 0.003492 & 0.008222 & 0.009074
\end{tabular}

As the temperature increased from $8{ }^{\circ} \mathrm{C}$ to $36{ }^{\circ} \mathrm{C}, \mathrm{F}_{\max }$ increased almost linearly for all mixtures. The maximum heat flow at high temperature $\left(36^{\circ} \mathrm{C}\right)$ was recorded for the MB-LF mixtures, regardless of the SP type. The maximum heat flow at low temperatures of 8 ㅇ $\mathrm{C}$ was recorded for MI-PNS-FA. A comparison between the MI-PNS-FA and MI-PCE1-FA mixtures at $8{ }^{\circ} \mathrm{C}$ and $15{ }^{\circ} \mathrm{C}$ shows that the heat flux was relatively high when PNS was incorporated with a given mixture design. However, at high temperatures the obtained values were comparable. 


\subsection{Effect of temperature on early-age compressive strength}

Figure 2 compares the 1-day compressive strengths of CEM mixtures prepared at different temperatures. The results show that the early-age compressive strength increased linearly with the increase in temperature. However, the SP and SCM types had different effects of compressive strength at $1 \mathrm{~d}$. Figure $2 \mathrm{a}$ shows that at $8 \stackrel{\circ}{ } \mathrm{C}$, the compressive strength of all CEM mixtures was almost identical. The results are in good agreement with the heat evolution of the investigated CEM mixtures (Fig. 1). At temperatures higher than ambient temperature, the MB-PCE1 mixtures made with FA exhibited higher compressive strengths than those made with LF. For CEM mixtures with FA and PNS, the compressive strength increased considerably at $36{ }^{\circ} \mathrm{C}$, as the higher temperature had a more significant impact on the binary FA+PNS system than the FA+ PCE1 system. The results from the calorimetry test also indicated that the major peak of heat evolution increased at higher rate at $36{ }^{\circ} \mathrm{C}$ when PNS was incorporated in the MB-FA CEM mixtures. This can be due to the less significant effect of elevated temperature on PNS performance than that of PCE. The effect of SP type on earlyage compressive strength of the MB-LF CEM mixtures at varying temperatures was insignificant. From the heat evolution profiles, it was apparent that the effect of temperature on the MB - LF CEM mixtures was independent of the SP type, and the heat flux was maintained almost constant.

Figure $2 b$ shows the effect of SCM on the 1-day compressive strength of the MP-PCE2 CEM mixtures. The compressive strength was higher for mixtures made with SF, which is in good agreement with the results from the calorimetry testing. However, the effect of temperature on the MP SEM mixtures was similar (increased compressive strength with the increase in temperature). On the contrary, the temperature had a distinct effect on the MI CEM mixtures prepared with FA and $S$ (Fig 2.c). This effect was more significant for CEM made with PNS and $\mathrm{S}$. As the temperature increased to $36^{\circ} \mathrm{C}$, the compressive strength improved more significantly for mixtures prepared with PNS and S. The effect of temperature on strength development of PNS+FA mixtures was less significant. The difference can be related to the higher reactivity of the slag compared to FA since the effect of temperature on the performance of PNS is reported to be limited.
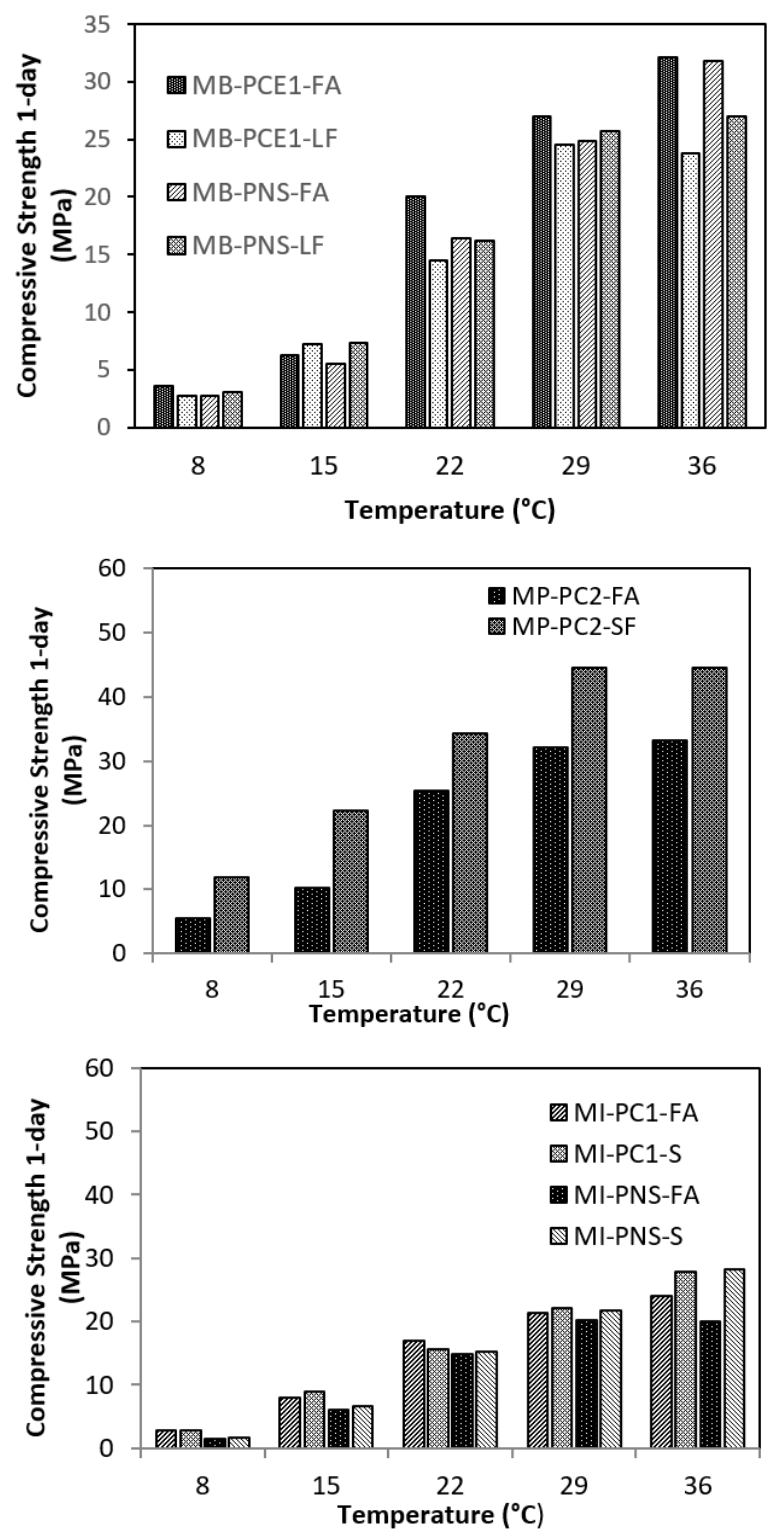

Figure 2. Compressive strength of CEM mixtures at different temperatures at 1 day.

Figure 3 shows the variations of the relative compressive strength of the various CEM mixtures compared to strength at $22{ }^{\circ} \mathrm{C}$ at different temperatures. A linear relationship can be established between the material temperature and 1-day compressive strength, regardless of the incorporated SP and SCM types. 


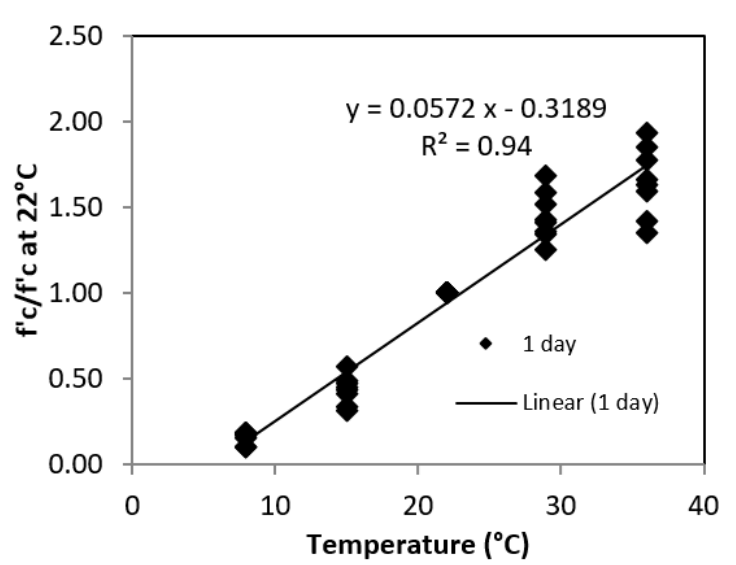

Figure 3. Variations of 1-day relative compressive strength of CEM mixtures.

\subsection{Effect of temperature on SP demand}

Figures 4 and 5 show the combined effect of temperature and SCM type on SP demand of CEM mixtures to maintain slump flow values within the targeted range. In general, results showed that a higher amount of PNS was required to maintain the target slump flow at varying temperatures. Furthermore, the results were conclusive that the temperature and SCM type had a different effect on the SP demand when PCE was applied. As shown in Fig. 4, the PCE demand increased in all samples as temperature elevated to 36 oC; however, at different rates. For example, the demand for PCE in the MB and MP mixtures increased by up to $50 \%$ as temperature was elevated to $36{ }^{\circ} \mathrm{C}$. At the same time, mixtures made with LF and SF were more sensitivity to temperature changes. Results of the hydration kinetics (Fig.1) showed that elevated temperatures increased the heat evolution significantly, especially in the MB and MP mixtures made with LF and SF. The results indicated that the increase in temperature reduced flowability, which can be mainly attributed to increased hydration rate, a quicker render of C$\mathrm{S}-\mathrm{H}$, and ultimately faster strength development [14]. Petit et al. [13] also reported that temperature and SCM type have a significant combined effect on the rate of adsorption of PCE onto cement particles by changing the rate of cement hydration and concentration of ions in the aqueous solution. The temperature can change the steric effect of the polymeric chains of the SP, which results in a higher initial yield stress value.

Figure 4.a shows that the demand for PCE1 in the MB mixtures prepared with $25 \%$ FA was lower than those prepared with the LF of the same content. This can be mainly related to the higher fineness and higher surface area of the LF compared to the FA, which can increase the PCE demand to secure a given fluidly [29,34]. The SP demand can also be affected by the dispersion state of solid particles, which changes the degree of adsorption of the chemical admixtures onto solid particles. According Lowke and Gehlen [35], SP adsorption is affected by the zeta potential. At higher more positive zeta potentials SP molecules are more likely adsorbed onto solid surfaces of the binder material. This can explain a higher tendency for the adsorption of PCE molecules onto the LF than FA due to its higher more positive zeta potentials in the pore solution of LF containing mixtures. Therefore, for a given replacement level, the $M B$ made with $L F$ required more PCE than that made with FA to secure the initially targeted slump flow.

For the MP mixtures, although cement replacement level for samples made with $25 \%$ FA was five times greater than those with SF (Fig. 4.b), the PCE demand was higher when SF was incorporated, which can correspond to the higher surface area of the SF. Besides, the morphology of FA particles can positively contribute to enhanced workability by providing a lubrication role [36]. Hence, the MP CEM mixture prepare with SF exhibited greater PCE1 demand. On the contrary, the PCE1 demand for the MI CEM made with 25\% FA was higher than those made with $25 \%$ S (Fig. 4.C). Reportedly, slag adsorbs significantly less admixture as compared to FA [37]. Consequently, the MI made with FA needed more PCE1 to attain the same flowability compared to the $\mathrm{MI}$ made with slag.
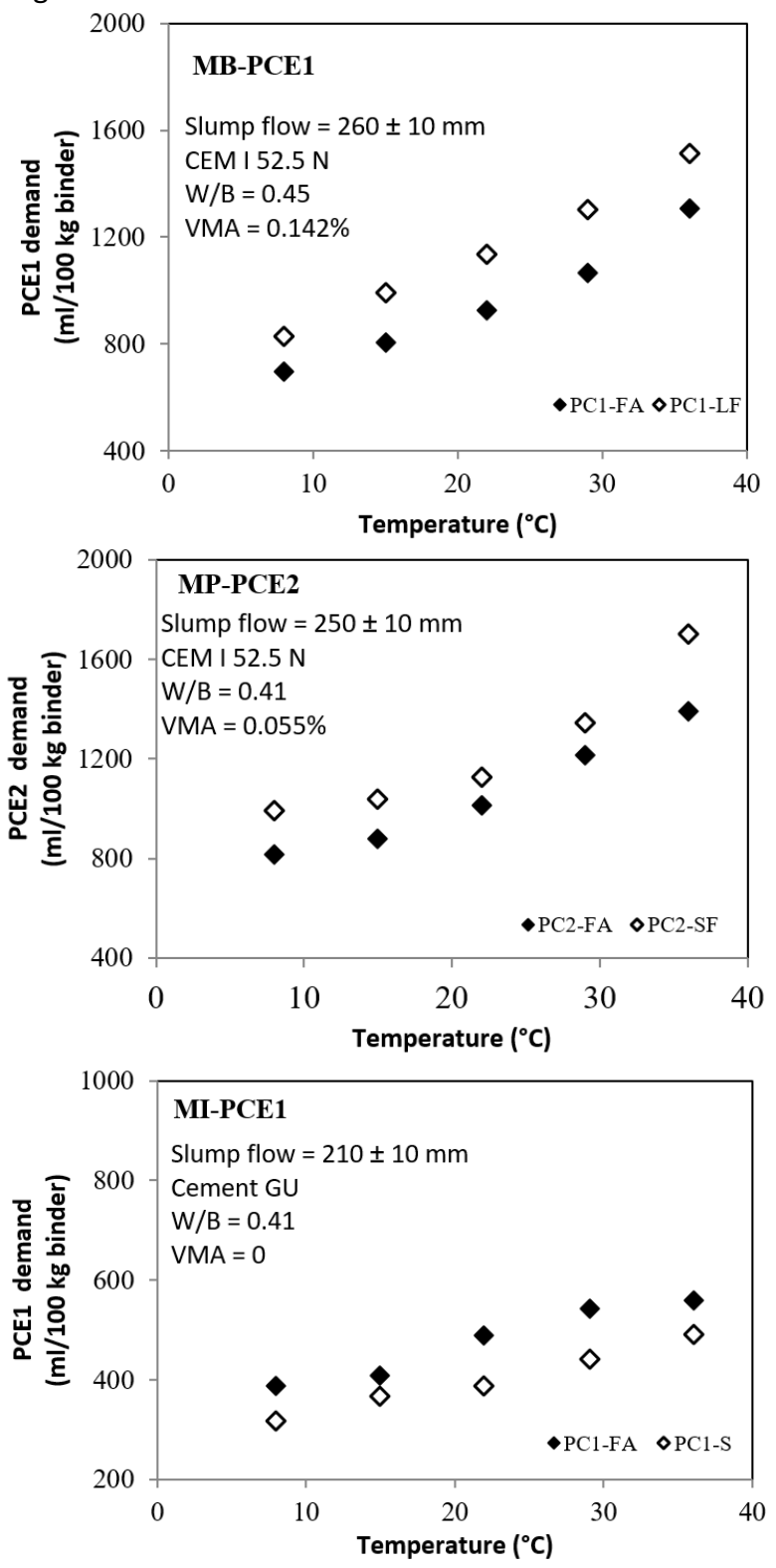

Figure 4. Effect of temperature on PCE demand of CEM mixtures 
Figure 5 shows the SP demand for the MB and MI CEM mixtures made with PNS and prepared at different temperatures. The figure shows similar tendencies in PNS demand the $\mathrm{MI}$ and $\mathrm{MB}$ mixtures made with $\mathrm{FA}, \mathrm{LF}$, or $\mathrm{S}$. Unlike PCE, the temperature did not increase the SP demand in mixtures made with PNS. The efficiency of the PNS increased with temperature resulting in a positive influence on flowability. The PNS demand can remain unchanged with the increase in temperature due to the opposing response of the electrostatic reactivity of the PNS and hydration kinetics of the binder. However, the incorporation of FA increased the PNS demand for the MB mixture (Fig. 5a). Two mechanisms can be used to explain this phenomenon. Firstly, it can be attributed to rapid adsorption of SP on aluminate phase instead of $A_{\mathrm{ft}}$ in mixtures with FA. The incorporation of FA can increase the aluminate phases, and the poly-condensates in SP tend to lose performance rapidly with the ongoing early hydration reaction, when they are directly adsorbed on aluminate phase of particles. Secondly, the adsorption of PNS onto primary hydration products after mixing is known to be relative to the content of sulfate ions [38]. The employed FA contains $1.36 \%$ of $\mathrm{SO}_{3}$ that is more than that in the $\mathrm{LF}(0.06 \%)$. Nakajima et al. [39] proposed a comprehensive model where a competitive equilibrium between sulfate ions and PNS was considered in terms of adsorption on hydrated cement. The authors reported that the flowability can decrease with the presence of alkali sulfate in cement paste. The increase of sulfate ions can lead to lower adsorption of PNS by the cement hydrates. Cement type is another factor that can change the adsorption rate of PNS onto the cement hydrates. The lower reactivity of $C_{3} A$ generally decreases the PNS adsorption onto the primary hydration product. The reduction of $\mathrm{C}_{3} \mathrm{~A}$ reactivity decreases sulfate ion consumption, attributing to an increase in sulfate ion concentration just after mixing, hence increasing PNS adsorption [40]. This can explain the higher demand for PNS in the MB mixtures in which cement with the lower $C_{3} A$ content was used. However, the effect of temperature on the PNS demand was low compared to mixtures prepared with PCE.

The demand for PNS in the MI mixtures decreased by up to $25 \%$ as temperature increased from $8{ }^{\circ} \mathrm{C}$ to $36^{\circ} \mathrm{C}$, though the changes were minimum between 15 and $36^{\circ} \mathrm{C}(5 \mathrm{~b})$. For the low temperature $\left(8^{\circ} \mathrm{C}\right)$, the $\mathrm{Ml}$ samples had greater PNS demand. It can be hypothesized that the impact of temperature on the hydration rate of cement was less critical than the constraining effect of temperature on the adsorption rate of PNS. The difference between the MB and the MI mixtures on the variation of PNS demand with temperature may also be due to the different characteristics of the CEM and their influence on the initial flowability.

\section{Conclusions}

In this study, the effect of ambient temperature during casting on early-age properties of the CEM associated with SCC mixtures designated for infrastructure, building construction, and precast applications was evaluated. Based on the results presented in this study, the following conclusions can be drawn:
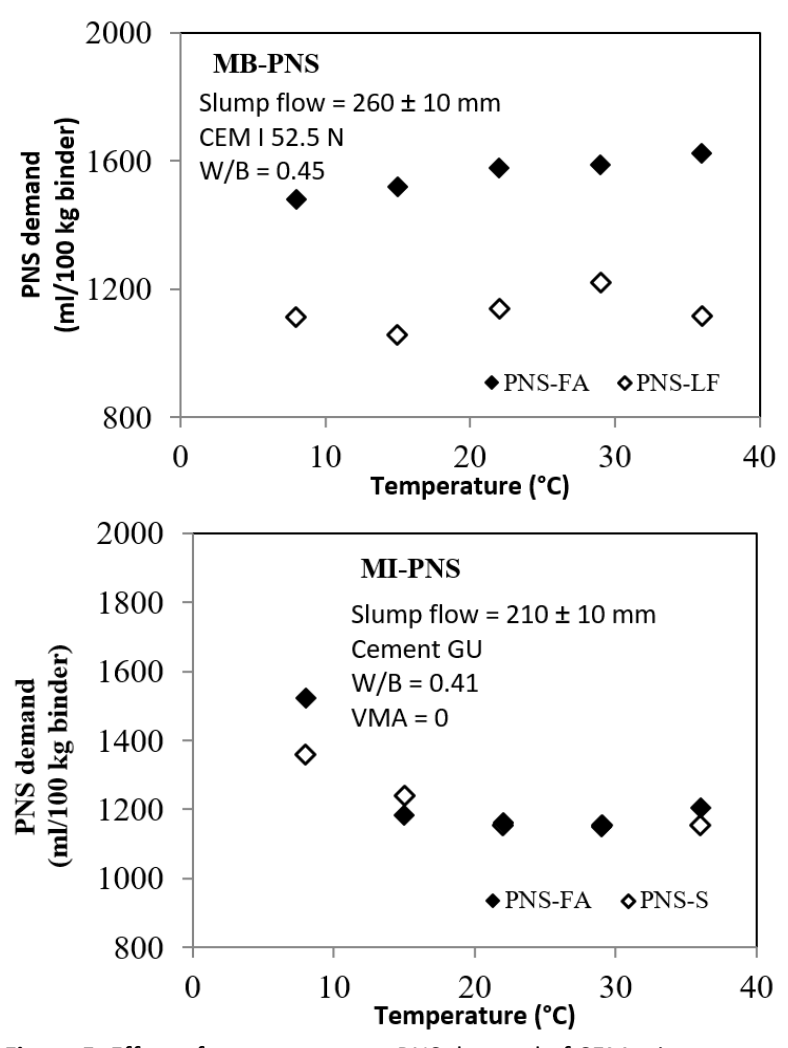

Figure 5. Effect of temperature on PNS demand of CEM mixtures.

1. The change in material temperature affected the heat evolution of the mixtures prepared with PCE significantly. Also, the type of SCM changed the performance of PCE differently at elevated temperatures compared to those prepared with PNS (e.g., decrease of the heat flow with the presence of FA and deceleration of heat evolution for mixtures made with LF). The increase in temperature resulted in high heat evolution and acceleration of the hydration in the CEM made with SF as compared with FA.

2. The results showed that the early-age compressive strength increased linearly with temperature. However, the SP and SCM types resulted in different effects on the 1-d strength. In general, at low temperatures, the compressive strength of all CEM mixtures was almost identical. At temperatures higher than the ambient temperature $(22 \stackrel{\circ}{\circ})$, the PCE mixtures made with FA exhibited higher compressive strength at $1 \mathrm{~d}$ than those made with LF. For mixtures prepared with FA and PNS, the strength development increased rapidly at 36 으, as the higher temperature had a more significant impact on the binary FA+PNS system than the FA+ PCE1 system.

3. The results showed that a higher amount of PNS was required to maintain the target slump flow at varying temperatures. Furthermore, the results were conclusive that the temperature and SCM type had a different effect on the SP demand when PCE was applied. The PCE demand increased in all samples as temperature elevated to 36 ㅇ; ; however, at different rates. Unlike PCE, temperature did not increase the SP demand in mixtures made with PNS. The efficiency of the PNS increased with 
temperature resulting in a positive influence on flowability.

\section{CRediT authorship statement}

Nima Farzadnia: Formal analysis, Writing-original draft, writing- review and editing, visualization.

Jing Pan: Investigation, Data curation, writing original draft

Kamal Khayat: Conceptualization, Methodology, Validation, writing- review and editing, supervision, Project administration, Funding acquisition

Eric Wirquin: Validation, supervision, Resources, Project administration, Funding acquisition

\section{References}

[1] V. Fernàndez-Altable, I. Casanova, Influence of mixing sequence and superplasticiser dosage on the rheological response of cement pastes at different temperatures. Cem Concr Res (2006) 36: 1222-1230. https://doi.org/10.1016/j.cemconres.2006.02.016

[2] C. Jolicoeur, J. Sharman, N. Otis, A. Lebel, M.-A. Simard, M. Page, The influence of temperature on the rheological properties of superplasticized cement pastes. Special Publication (1997) 173: 379-406.

[3] T. Nawa, H. Ichiboji, M. Kinoshita, Influence of temperature on fluidity of cement paste containing superplasticizer with polyethylene oxide graft chains. Special Publication (2000) 195: 181-194.

[4] G. Ovarlez, P. Coussot, Physical age of soft-jammed systems. Phys Rev E. (2007) 76: 011406. https://doi.org/10.1103/PhysRevE.76.011406

[5] S. Goto, D.M. Roy, The effect of $w / c$ ratio and curing temperature on the permeability of hardened cement paste. Cem Concr Res (1981) 11: 575-579. https://doi.org/10.1016/0008-8846(81)90087-9

[6] K.O. Kjellsen, R.J. Detwiler, Reaction kinetics of Portland cement mortars hydrated at different temperatures. Cem Concr Res (1992) 22: 112-120. https://doi.org/10.1016/0008-8846(92)90141-H

[7] B. Lothenbach, F. Winnefeld, C. Alder, E. Wieland, P. Lunk, Effect of temperature on the pore solution, microstructure and hydration products of Portland cement pastes. Cem Concr Res (2007) 37: 483491. https://doi.org/10.1016/j.cemconres.2006.11.016

[8] P. Termkhajornkit, R. Barbarulo, Modeling the coupled effects of temperature and fineness of Portland cement on the hydration kinetics in cement paste. Cem Concr Res (2012) 42: 526-538. https://doi.org/10.1016/j.cemconres.2011.11.016

[9] E. Wirquin, H. Kada, P. Herin, Development of a Plane Isothermal Calorimeter: Relating Apparent Activation Energy of Concrete and the Corresponding Mortar. Journal of ASTM International (2008) 5: 112. https://doi.org/10.1520/JAl101057

[10] W. Schmidt, H. Brouwers, H.-C. Kühne, B. Meng, Influences of superplasticizer modification and mixture composition on the performance of self-compacting concrete at varied ambient temperatures. Cem Concr Compos (2014) 49: 111-126. https://doi.org/10.1016/j.cemconcomp.2013.12.004

[11] M. Nehdi, S. Al Martini, Effect of temperature on oscillatory shear behavior of portland cement paste incorporating chemical admixtures. J Mater Civ Eng (2007) 19: 1090-1100. https://doi.org/10.1061/(ASCE)0899-1561(2007)19:12(1090)

[12] W. Schmidt, J. Brouwers, H.-C. Kühne, B. Meng, Effects of superplasticizer and viscosity-modifying agent on fresh concrete performance of SCC at varied ambient temperatures, in: Design, Production and Placement of Self-Consolidating Concrete, Springer, 2010, 65-77. https://doi.org/10.1007/978-90-481-9664-7 6

[13] J.-Y. Petit, E. Wirquin, K.H. Khayat, Effect of temperature on the rheology of flowable mortars. CemConcr Compos (2010) 32: 43-53. https://doi.org/10.1016/j.cemconcomp.2009.10.003

[14] K. Yamada, T. Yanagisawa, S. Hanehara, Influence of temperature on the dispersibility of polycarboxylate type superplasticizer for highly fluid concrete. 1999, 437-448.

[15] J.-Y. Petit, K.H. Khayat, E. Wirquin, Coupled effect of time and temperature on variations of yield value of highly flowable mortar. Cem Concr Res (2006) 36: 832-841. https://doi.org/10.1016/i.cemconres.2005.11.001

[16] R.J. Flatt, Y.F. Houst, A simplified view on chemical effects perturbing the action of superplasticizers. Cem Concr Res (2001) 31: 1169-1176. https://doi.org/10.1016/S0008-8846(01)00534-8
[17] L. Yijin, Z. Shiqiong, Y. Jian, G. Yingli, The effect of fly ash on the fluidity of cement paste, mortar, and concrete. 2004, 339-345.

[18] H.-C. Kühne, W. Schmidt, B. Meng, The influence of temperature on selfcompacting concrete in presence of superplasticizer and additional admixtures, 2007, 405-10.

[19] D. Myers, Surfaces, interfaces, and colloids, Wiley-Vch New York etc., 1999. https://doi.org/10.1002/0471234990

[20] V.H. Dodson, Concrete admixtures, Springer Science \& Business Media, 2013.

[21] L. Du, K.J. Folliard, Mechanisms of air entrainment in concrete, Cem Concr Res (2005) 35: 1463-1471. https://doi.org/10.1016/j.cemconres.2004.07.026

[22] ASTM C 494/C 494M, Standard Specification for Chemical Admixtures for Concrete, 2019.

[23] M. AASHTO, 194M/M 194-06, Standard Specification for Chemical Admixtures for Concrete," American Association of State and Highway Transportation Officials, Washington, DC., 2006.

[24] ASTM C260, Standard specification for air-entraining admixtures for concrete, ASTM International, West Conshohocken, PA, 2010.

[25] J.J. Assaad, J. Harb, E. Chakar, Relationships between key ASTM test methods determined on concrete and concrete-equivalent-mortar mixtures. Journal of ASTM International (2009) 6: 1-13. https://doi.org/10.1520/JAl101735

[26] T.K. Erdem, K.H. Khayat, A. Yahia, Correlating rheology of selfconsolidating concrete to corresponding concrete-equivalent mortar, ACI Mater J (2009) 106: 154. https://doi.org/10.14359/56462

[27] ASTM, C 305, Standard practice for mechanical mixing of hydraulic cement pastes and mortars of plastic consistency, ASTM International, West Conshohocken, PA, 1999.

[28] EFNARC, Guidelines for Viscosity Modifying Admixtures for Concrete, 2006.

[29] C. Jolicoeur, M.-A. Simard, Chemical admixture-cement interactions: phenomenology and physico-chemical concepts. Cem Concr Compos (1998) 20: 87-101. https://doi.org/10.1016/S0958-9465(97)00062-0

[30] N. Ghafoori, H. Diawara, Influence of temperature on fresh performance of self-consolidating concrete. Constr Build Mater (2010) 24: 946-955. https://doi.org/10.1016/j.conbuildmat.2009.11.023

[31] ASTM C1437, Standard test method for flow of hydraulic cement mortar, ASTM International, West Conshohocken, PA, 2007.

[32] ASTM C109, standard test method for compressive strength of hydraulic cement mortars, ASTM International, West Conshohocken, PA, 2008.

[33] ASTM C511, Standard specification for mixing rooms, moist cabinets, moist rooms, and water storage tanks used in the testing of hydraulic cements and concretes, ASTM International, West Conshohocken, PA, 2013.

[34] G. Ferrari, T. Cerulli, P. Clemente, M. Dragoni, M. Gamba, F. Surico, Influence of carboxylic acid-carboxylic ester ratio of carboxylic acid ester superplasticizer on characteristics of cement mixtures. Special Publication (2000) 195: 505-520.

[35] D. Lowke, C. Gehlen, Effect of pore solution composition on zeta potential and superplasticizer adsorption, 2015: 253.

[36] W. Aiqin, Z. Chengzhi, S. Wei, Fly ash effects: I. The morphological effect of fly ash. Cem Concr Res (2003) 33: 2023-2029. https://doi.org/10.1016/S0008-8846(03)00217-5

[37] O. Burgos-Montes, M. Palacios, P. Rivilla, F. Puertas, Compatibility between superplasticizer admixtures and cements with mineral additions. Constr Build Mater (2012) 31: 300-309. https://doi.org/10.1016/j.conbuildmat.2011.12.092

[38] V. Fernon, A. Vichot, N. Le Goanvic, P. Colombet, F. Corazza, U. Costa, Interaction between Portland cement hydrates and polynapthalene sulfonates. Special Publication (1997) 173: 225-248.

[39] Y. Nakajima, T. Goto, K. Yamada, A Practical Model for the Interactions Between Hydrating Portland Cements and Poly - $\beta$ Naphthalene Sulfonate Condensate Superplasticizers, J Am Ceram Soc (2005) 88: 850-857. https://doi.org/10.1111/j.1551-2916.2005.00206.x

[40] S. Hanehara, K. Yamada, Rheology and early age properties of cement systems. Cem Concr Res (2008) 38: 175-195. https://doi.org/10.1016/j.cemconres.2007.09.006 